\title{
X-ray Gauge Monitoring of LLNL Replica Carbon Production Process
}

\author{
Daniel L. Lewis
}

December 1990

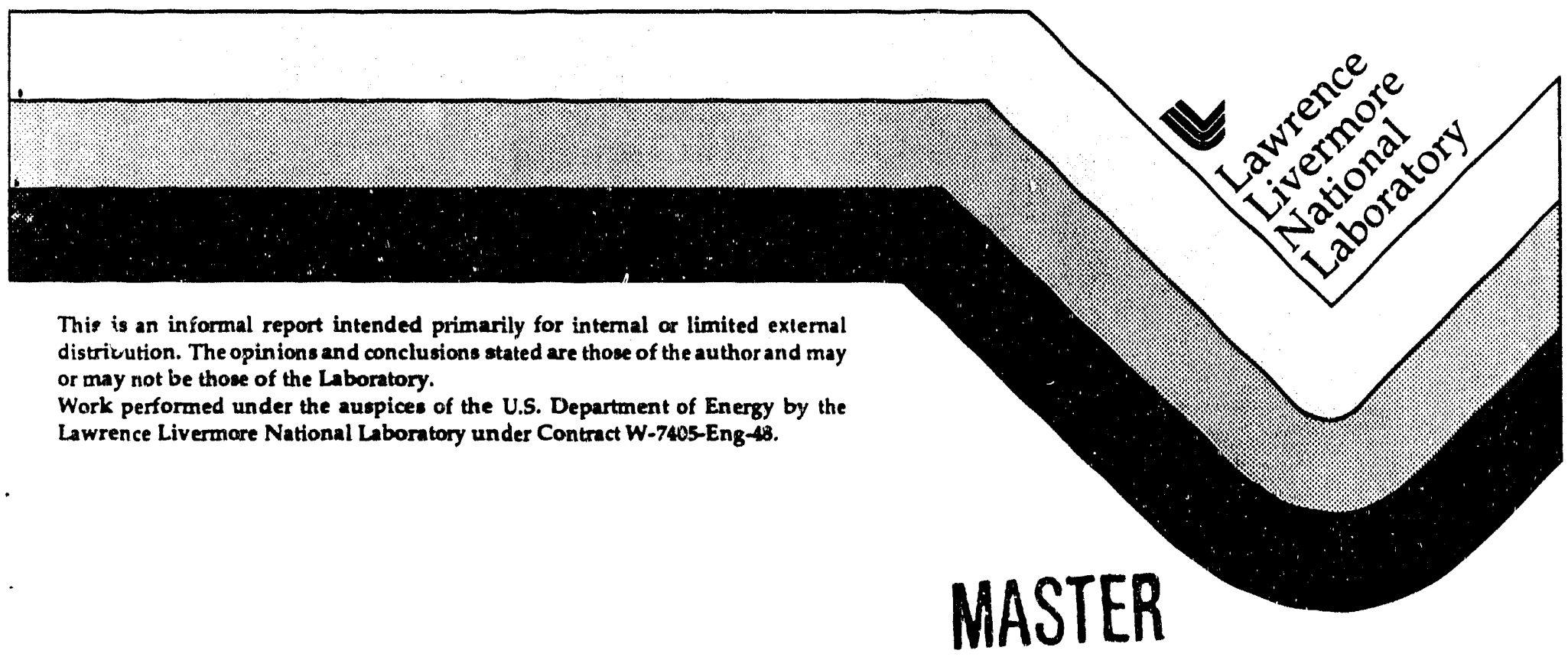




\section{DISCLAIMER}

This document was prepared as an account of work sponsored by an agency of the United States Government. Neither the United States Government nor the University of California nor any of their employees, makes a. y warranty, express or implied, or assumes any legal liability or responsibility for the accuracy, completeness, or usefulness of any information, apparatus, product, or process disclosed, or represents that its use would not infringe privately owned rights. Reference herein to any specific commercial products, process, or service by trade name, trademark, manufacturer, or otherwise, does not necessarily constitute or imply its endorsement, recommendation, or favoring by the United States Government or the University of California. The views and opinions of authors expressed herein do not necessarily state or reflect those of the United States Government or the University of California, and shall not be used for advertising or product endorsement purposes.

This report has been reproduced

directly from the best available copy.

Available to DOE and DOE contractors from the Office of Scientific and Technical Information

$$
\text { P.O. Box 62, Oak Ridge, TN } 37831
$$

Prices avalable from 1615 ) 576-8401, FTS 626-8401.

Available to the pubilic from the

National Technical Information Service

U.S. Department of Commerce

5285 Port Royal Rd.

Springfield, VA 2210

\section{Papercopy Prices}

$\mathrm{AO}_{2}$

$\mathrm{AO3}$

A04

A05

A06

A07

A08

A09

A10

A11

A12

A13

A14

A15

A16

A17

A18

A19

A20

A ?1

A22

A23

A24

A25

A99
$1-10$

11- 50

51- 75

76-100

101-125

126-150

151-175

176-200

201-225

226-250

251-275

276-300

301-325

326-350

351-375

376-400

401-425

426-450

451-475

476-500

501-525

526-550

551-575

576-600

601 \& UP 


\title{
$X$-ray Gauge Monitoring \\ of LLNL Replica Carbon \\ Production Process
}

\author{
by
}

Daniel L. Lewis

This report contains results of a series of $\mathrm{x}$-ray gauging measurements perforned on bars tracked through the LLNL replica carbon production process.

We were tasked with monitoring a few salt bars through the entire production process to identify any possible problem areas. The process consists of five major steps:

1) Pressing fine sodium chloride crystals into a uniform salt bar,

2) Sintering the salt bar,

3) Infusing the bar with a phenolic polymer solution and convection oven drying it to remove the acetone solvent,

4) Carbonizing the polymer, and

5) Extracting the salt with water and freeze-drying the final carbon foam bar.

After pressing the salt bars, six typical bars were selected for characterization: LS1875, LS1876, LS1879, LS1881, LS1883, and LS1886. These six bars were to be gauged after each of the five production steps to check for any inhomogeneity introductions. Two of the bars, however, were damaged during the final production step, resulting in complete process information for only four of the six bars. This report contains only the information gathered for these four bars. The data obtained for the other two bars, prior to damage, showed no significant difference from the data presented here.

The $\mathrm{x}$-ray gauge was used to determine the homogeneity of a bar by measuring the photon transmission through its thickness and converting it to areal density. The areal density was calculated from the transmission measurement, the relative abundance of the elements present, and the elements' tabulated cross section values 1 . The density and composition of the bars at various stages of processing required that we use two different photon sources. Differences in scattering and errors in cross section values may introduce small errors in the calculated areal densicies. Although these errors may affect the absolute areal density value by several perceni, they are negligible when normalized to the bar's mean areal density. Therefore, all gauging results are presented as a percent deviation from the mean areal density of the bar.

The studied bars were approximately $4.5^{\prime \prime}$ long by $1.0^{\prime \prime}$ wide by $0.5^{\prime \prime}$ thick and were to be gauged through the thickness dimension. Each bar was gauged at 32 points in a uniform matrix as shown in Figure 1. We gauged the bars in the same location after each process step so that subsequent results could be compared. The gauge counting time was chosen to obtain one-half percent counting statistics precision in the results. The salt, with a bulk density of about $1.4 \mathrm{~g} / \mathrm{cm}^{3}$, required the use of an americium-241 radioisotope source that produces $59.5 \mathrm{keV}$ photons. The americium-241 source was used for gauging

\footnotetext{
${ }^{1}$ E. F. Plechaty, D. E. Cullen, and R. J. Howerton, Tables and Graphs of Photon-Interaction Cross Sections From $0.1 \mathrm{keV} 10100 \mathrm{MeV}$ Derived From The LLL Evaluated-Nuclear-Data Library, Lawrence Livermore Laboratory, Livermore, CA UCRL-50400, Vol. 6, Rev. 3 (1981).
} 
after the first four process steps. The final replica carbon foam bar, with a bulk density of about $50 \mathrm{mg} / \mathrm{cm}^{3}$, required the use of an iron-55 source that produces $5.9 \mathrm{keV}$ photons.

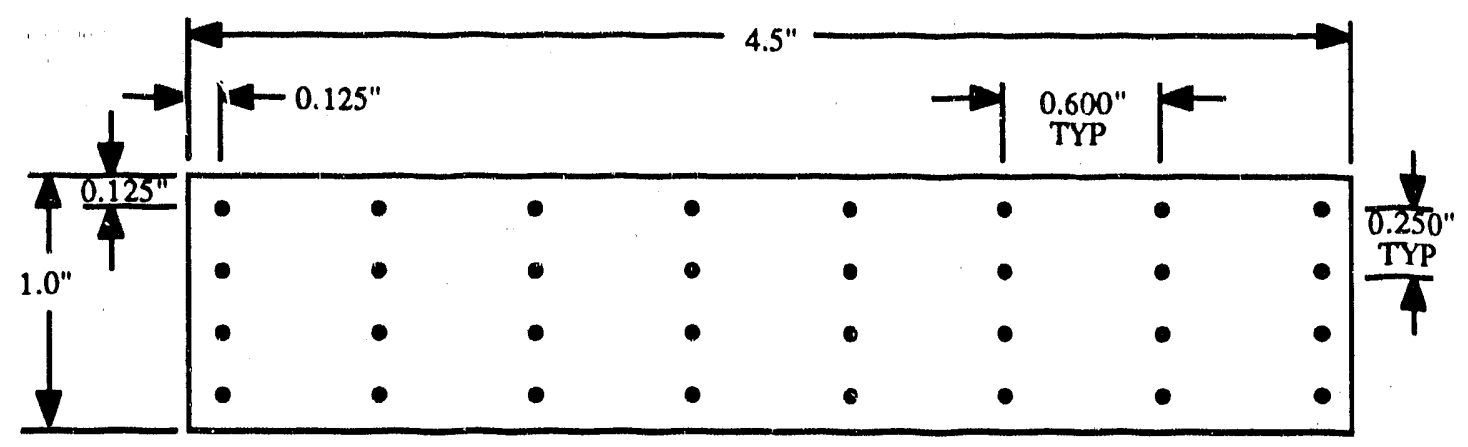

Figure 1 - Layout of Gauging Point Locations

The first step was to press the fine sodium chloride crystals into salt bars. The gauging results showed that the pressing of the salt bars was a very uniform process. The density variations were only about $+/-2 \%$ as can be seen from the contour plots of Figure 2. The plots were generated using a software package called WINGZ with each intersection on the plot representing a gauged point and the intermediate integration and shading being performed by the software. The plots do not show any definite trends in the data as to the locations of higher or lower areal density regions. Table 1 summarizes the areal density gauging results. The pressed salt bars are very uniform in areal density.

Table 1

Salt Bar Areal Densities After Pressing

$\begin{array}{lccc}\text { Mean Areal } & \begin{array}{c}\text { Standard } \\ \text { Density } \\ \left(\mathrm{g} / \mathrm{cm}^{2}\right)\end{array} & \begin{array}{c}\text { Deviation } \\ (\%)\end{array} & \begin{array}{c}\text { Min }>\text { Max } \\ \text { Range } \\ (\%)\end{array} \\ \text { LS } 1875 & 1.542 & 0.724 & 2.270 \\ \text { LS } 1881 & 1.626 & 0.391 & 1.722 \\ \text { LS } 1883 & 1.627 & 0.523 & 1.967 \\ \text { LS } 1886 & 1.525 & 0.608 & 2.624\end{array}$

The second step consisted of sintering the salt bars to fuse the salt crystals together. The results can ba found in the plots of Figure 3. They show no significant change in the homogeneity of the bars. Table 2 summarizes the areal density gauging results and shows that there was a slight density increase due to the shrinkage of the bars.

Table 2

Salt Bar Areal Densities After Sintering

$\begin{array}{lccc}\text { Mean Areal } & \begin{array}{c}\text { Standard } \\ \text { Density } \\ \left(\mathrm{g} / \mathrm{cm}^{2}\right)\end{array} & \begin{array}{c}\text { Meviation } \\ (\%)\end{array} & \begin{array}{c}\text { Range } \\ (\%)\end{array} \\ \text { Bar ID\# } & 1.570 & 0.573 & \\ \text { LS } 1875 & 1.655 & 0.477 & 2.624 \\ \text { LS } 1881 & 1.652 & 0.512 & 1.970 \\ \text { LS } 1883 & 1.549 & 0.641 & 2.124 \\ \text { LS } 1886 & & & 2.337\end{array}$

Next, the bars were infused with a phenolic polymer solution and then convection oven dried to remove the acetone solvent. We gauged the bars and reduced the data as if all the $x$-ray attenuation was due to salt. The contour plots of Figure 4A show that a definite density pattern has developed in the bars. They indicate that the areal density is lower in 
the center and higher at the edges of the bars. Examination of Table 3A shows that the average areal density of the bars increased due to the addition of the polymer, as expected, and also, more importantly, that the density variation increased. Photon attenuation is a very strong function of $Z$, atomic number. It is approximately proportional to $Z^{4}$. Thus, interpreting the additional attenuation arising from the polymer, (containing carbon, hydrogen, and oxygen), as if it were sodium chloride does not provide a useful estimate of the uniformity of the polymer.

Table 3A

Areal Densities After Polymer Infusion (Polymer \& Salt)

$\begin{array}{cccc} & \text { Mean Areal } & \text { Standard } & \text { Min } \rightarrow \text { Max } \\ \text { Bar ID\# } & \text { Density } & \text { Deviation } & \text { Range } \\ & \left(\% / \mathrm{cm}^{2}\right) & (\%) & (\%)\end{array}$

$\begin{array}{llll}\text { LS } 1875 & 1.644 & 0.685 & 2.481 \\ \text { LS } 1881 & 1.720 & 0.697 & 3.360 \\ \text { LS } 1883 & 1.718 & 0.668 & 3.190 \\ \text { LS } 1886 & 1.618 & 0.775 & 3.004\end{array}$

We separated the attenuation caused by the polymer from the attenuation caused by the salt. Since the gauge measurements were made in the same spots, we subtracted the data obtained from the previous gauging step. The assumption was made that this operation would remove all density variations due to the salt bar itself leaving only the contributions of the added polymer. This data was then converted to polymer areal densities and the results can be found in the plots of Figure 4B and in Table 3B. The areal density variations are extremely large and indicate that the infused polymer distribution is not very uniform. However, these results are susceptible to large errors due to the manner in which they were obtained and the fact that the polymer is practically transparent to the gauging photon energy. The uncertainty, based on standard counting statistics, was calculated to have a standard deviation of about 30 percent. Therefore, the conclusion from this data is that the polymer areal densities vary $+1-45 \%$ with $30 \%$ uncertainty, indicating the presence of real density variations in the polymer, but of an uncertain magnitude.

Table 3B

Areal Densities After Polymer Infusion (Polymer Only)

$\begin{array}{lccc}\text { Bar ID\# } & \begin{array}{c}\text { Mean Areal } \\ \text { Density } \\ \left(\mathrm{mg} / \mathrm{cm}^{2}\right)\end{array} & \begin{array}{c}\text { Standard } \\ \text { Deviation } \\ (\%)\end{array} & \begin{array}{c}\text { Min } \rightarrow \text { Max } \\ \text { Range } \\ (\%)\end{array} \\ \text { LS } 1875 & 137.575 & 12.534 & \\ \text { LS } 1881 & 121.085 & 16.555 & 56.314 \\ \text { LS } 1883 & 121.923 & 19.788 & 63.710 \\ \text { LS } 1886 & 127.329 & 19.705 & 94.545 \\ \text { L } & & & 70.007\end{array}$

After the bars had been carbonized, we gauged them and, again, corrected for the attenuation of the salt. The residual attenuation was interpreted as arising only from the carbon. This data is shown in Figure 5 and Table 4. The areal density contours of the carbon within the salt are very similar to that observed for the polymer on the previous step. These results are subject to large statistical uncertainty as in the previous step and, in addition, there appears to be an added influence from further densification of the salt during carbonization. 
Table 4

Areal Densities After Polymer Carbonization (Carbon Only)

$\begin{array}{lccc}\text { Bar ID\# } & \begin{array}{c}\text { Mean Areal } \\ \text { Density } \\ \left(\mathrm{mg} / \mathrm{cm}^{2}\right)\end{array} & \begin{array}{c}\text { Standard } \\ \text { Deviation } \\ (\%)\end{array} & \begin{array}{c}\text { Min } \rightarrow \text { Max } \\ \text { Range } \\ (\%)\end{array} \\ \text { LS } 1875 & 193.825 & 15.217 & \\ \text { LS } 1881 & 198.260 & 13.371 & 53.327 \\ \text { LS } 1883 & 210.066 & 17.083 & 58.825 \\ \text { LS } 1886 & 198.782 & 14.760 & 67.839 \\ & & & 65.143\end{array}$

The fifth and final step in the process uses water to extract the salt from the bar. It is then freeze-dryed to obtain the finished replica carbon foam bar. The gauge results can be found in the plots of Figure 6 and in Table 5. These plots indicate, undoubtedly, that a substantial density gradient from center to edge exists in all finished carbon bars of this study.

Table 5

Areal Densities of the Final Replica Carbon Foam

$\begin{array}{cccc} & \begin{array}{c}\text { Mean Areal } \\ \text { Density } \\ \left(\mathrm{mg} / \mathrm{cm}^{2}\right)\end{array} & \begin{array}{c}\text { Standard } \\ \text { Deviation } \\ (\%)\end{array} & \begin{array}{c}\text { Min } \rightarrow \text { Max } \\ \text { Range } \\ \text { Bar ID\# }\end{array} \\ & & & \\ \text { LS } 1875 & 55.581 & 8.888 & 31.485 \\ \text { LS } 1881 & 55.109 & 9.932 & 33.388 \\ \text { LS } 1883 & 55.493 & 9.961 & 30.634 \\ \text { LS } 1886 & 58.493 & 8.221 & 28.892\end{array}$

In conclusion, the $x$-ray gauge results indicate that the polymer infusion process for these bars is extremely non-uniform. Large density gradients of the polymer in the bars ultimately results in large density gradients in the final product. The gauge reports that the center to edge gradients are on the order of $30 \%$ with less than $1 \%$ uncertainty. In addition, it must be remembered that these results are strictly two-dimensional. The variation could be much worse in three dimensions depending on the geometry of the density variations. A computed tomography study of the density variation in three dimensions is currently underway for these carbon bars. 
Figure 2 - Uniformity of Salt Bars After Pressing
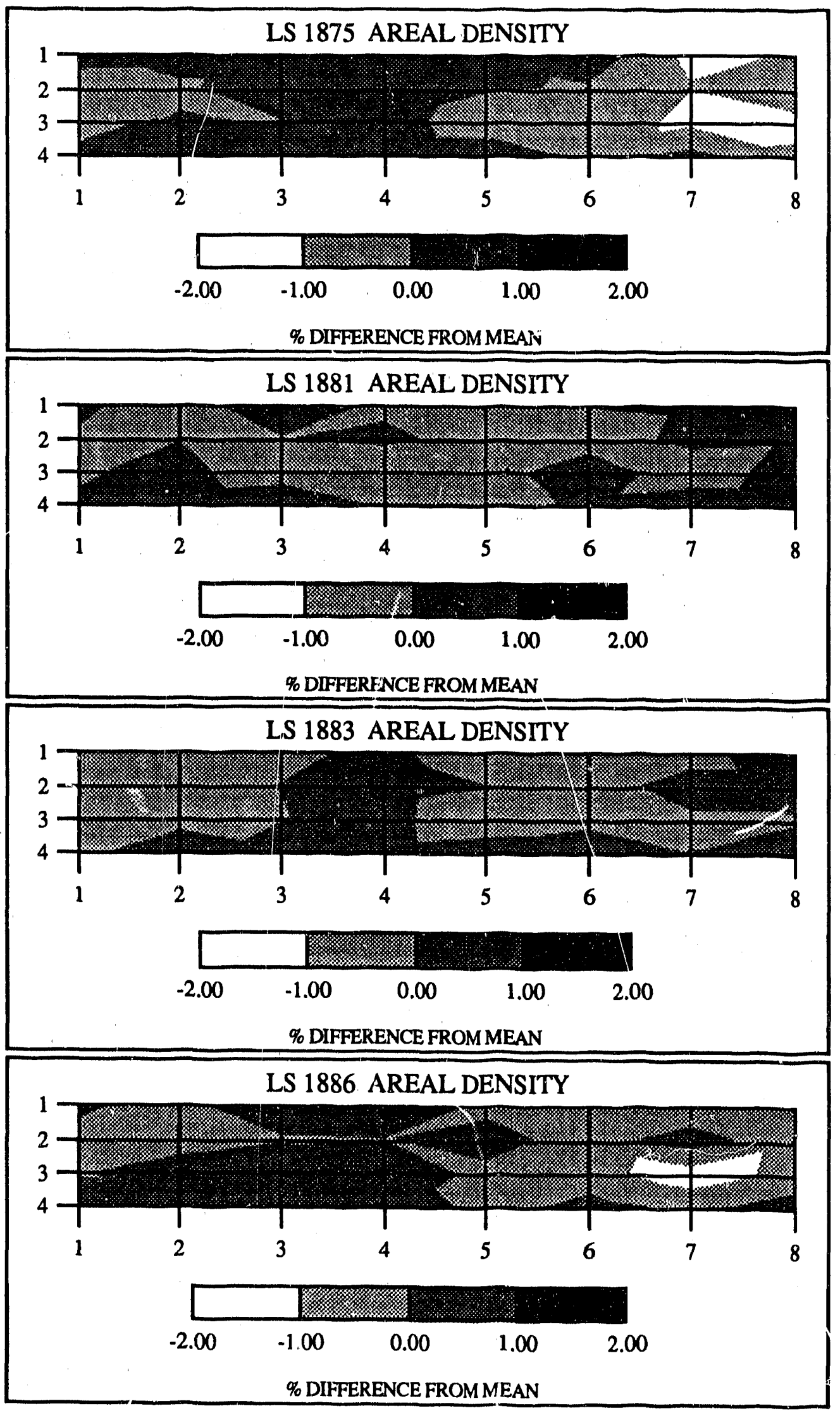
Figure 3 - Uniformity of Salt Bars After Sintering
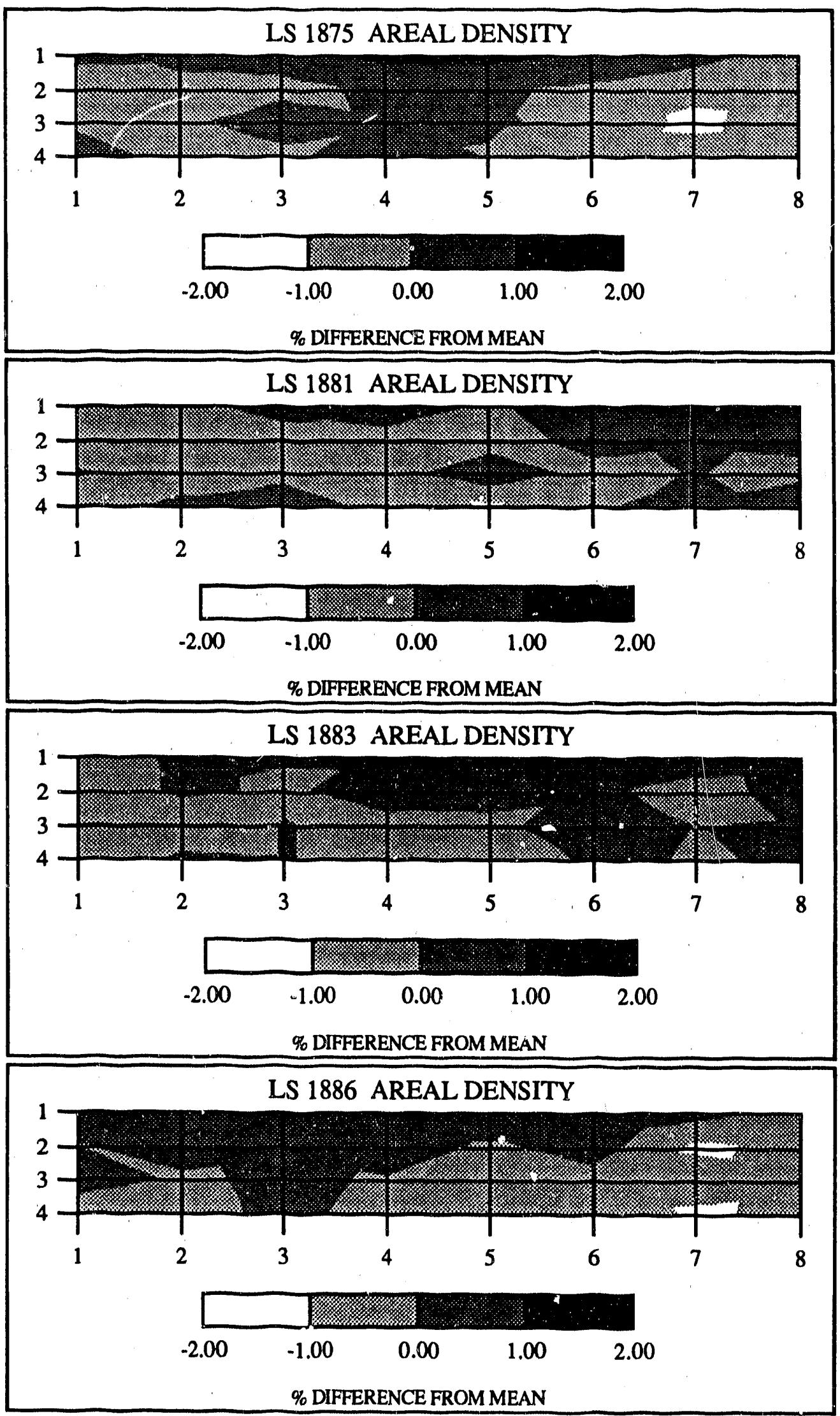
Figure 4A - Uniformity After Polymer Infusion (Polymer \& Salt)
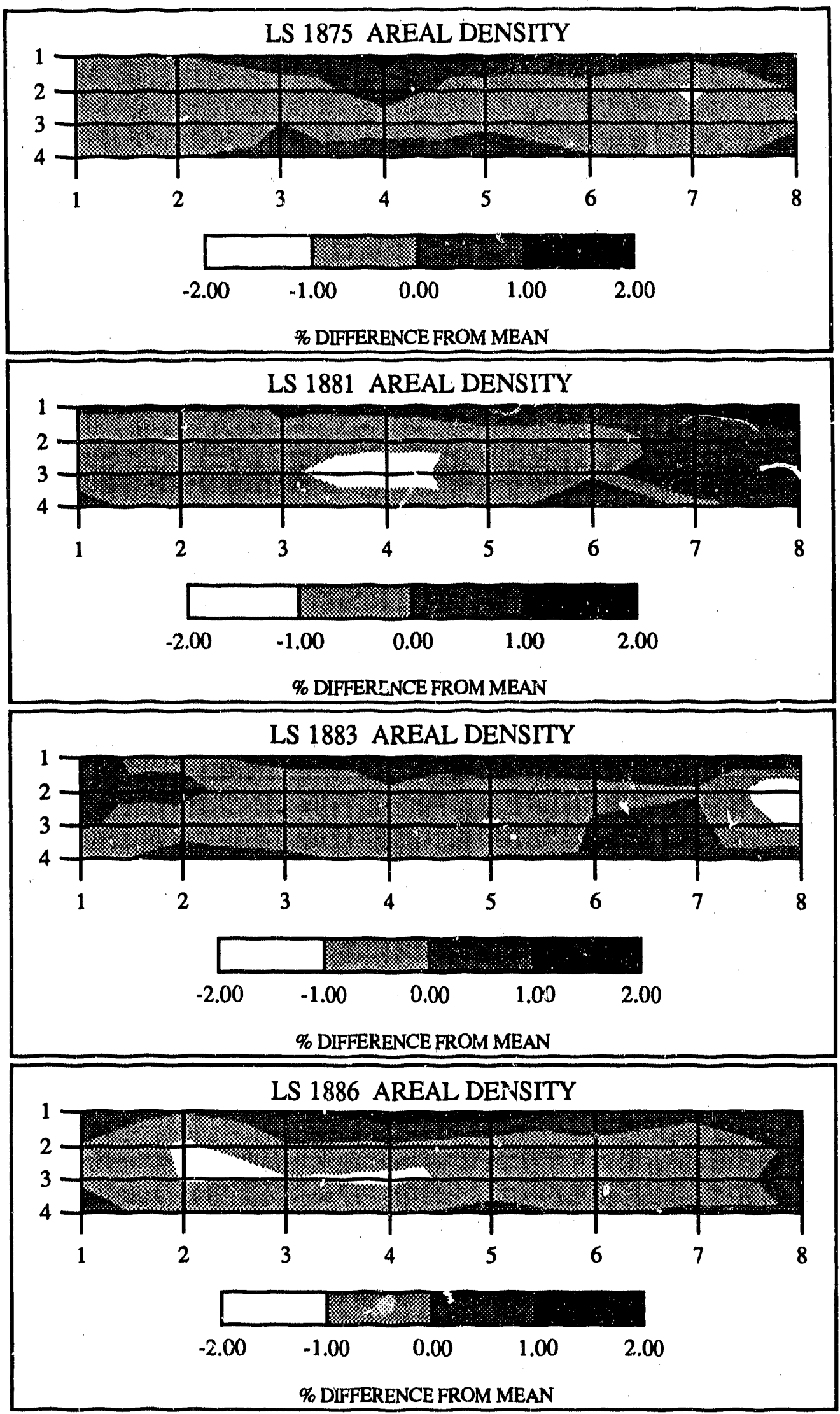
Figure 4B - Uniformity After Polymer Infusion (Polymer Only)
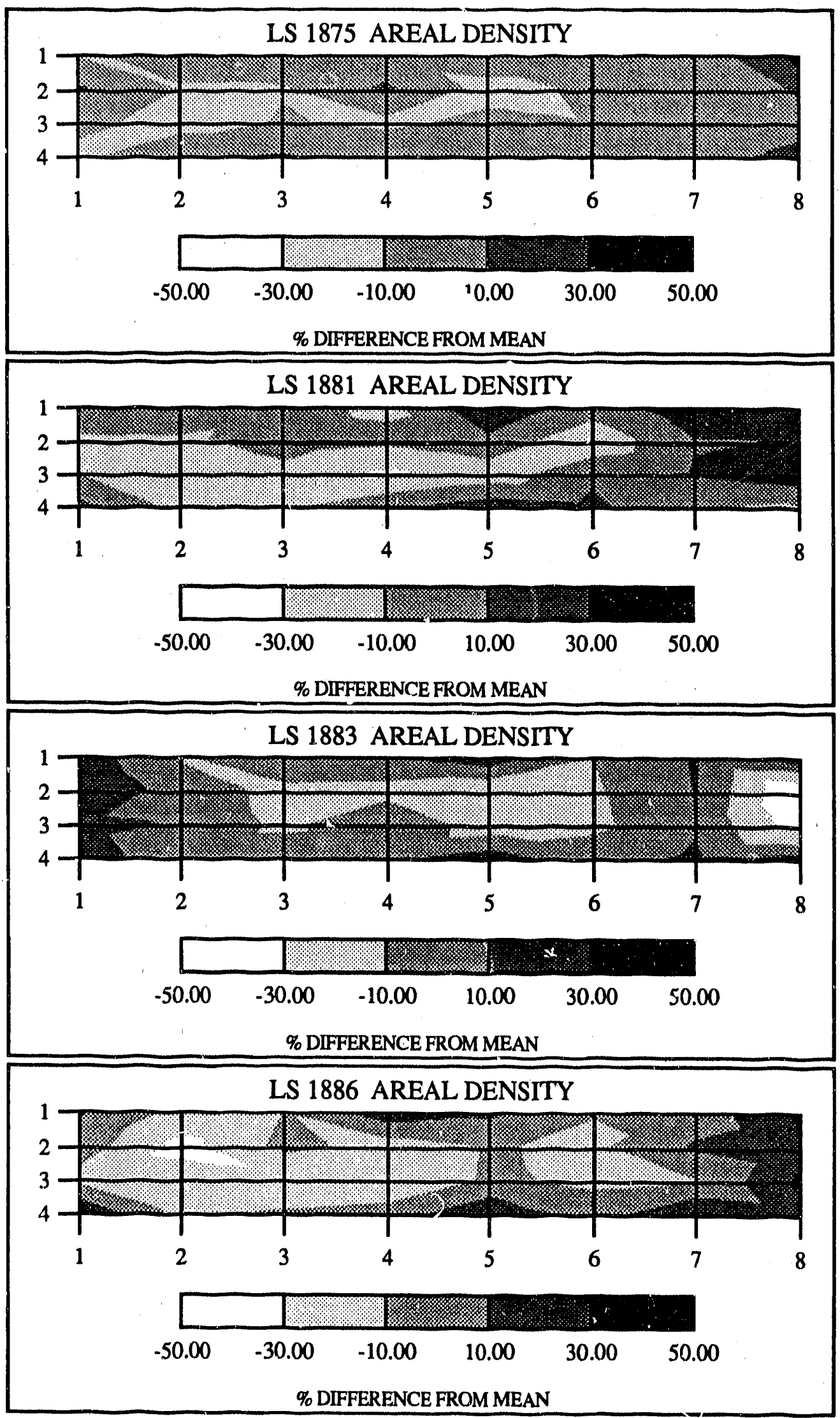
Figure 5 - Uniformity After Polymer Carbonization (Carbon Only)
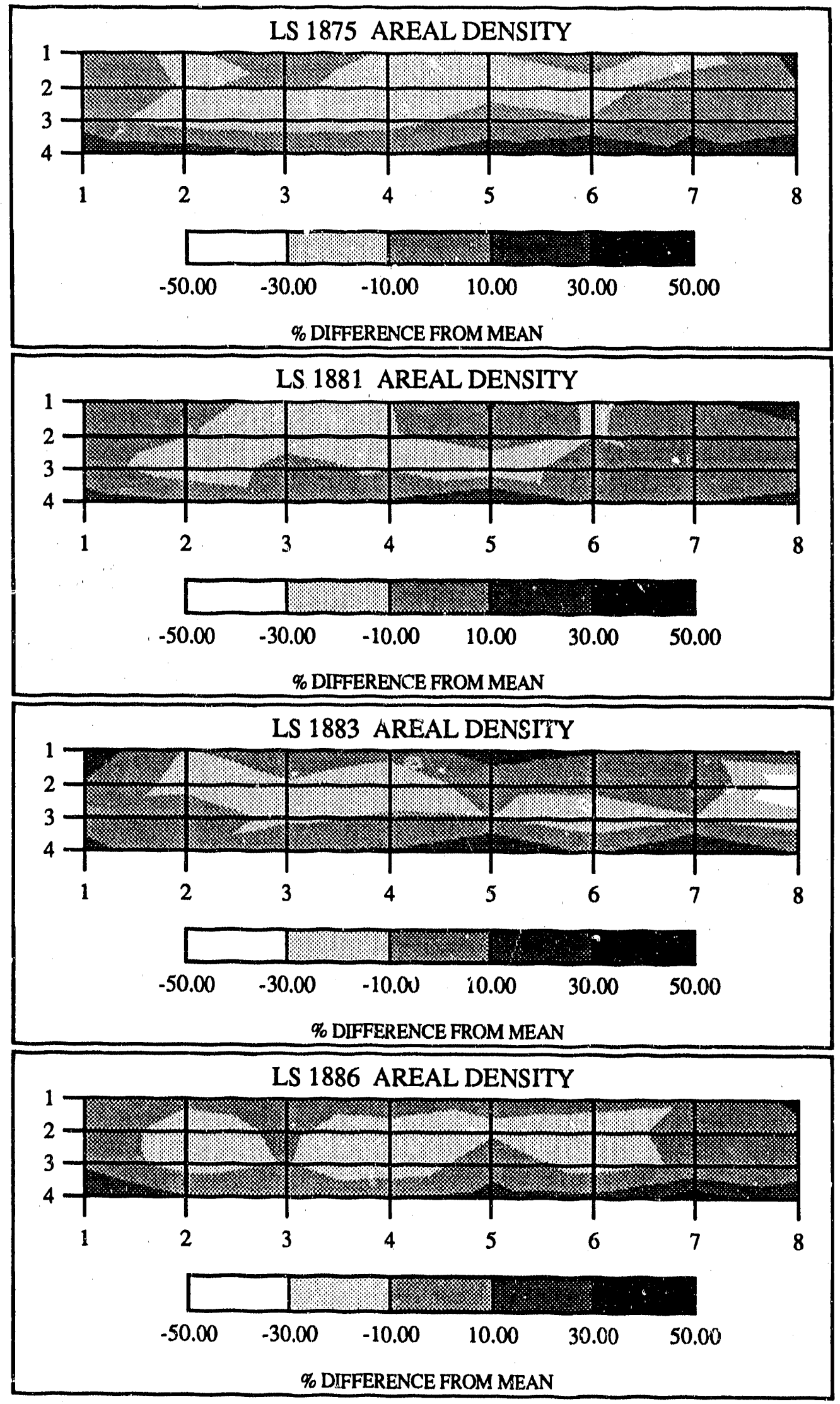
Figure 6 - Uniformity of Final Replica Carbon Foam
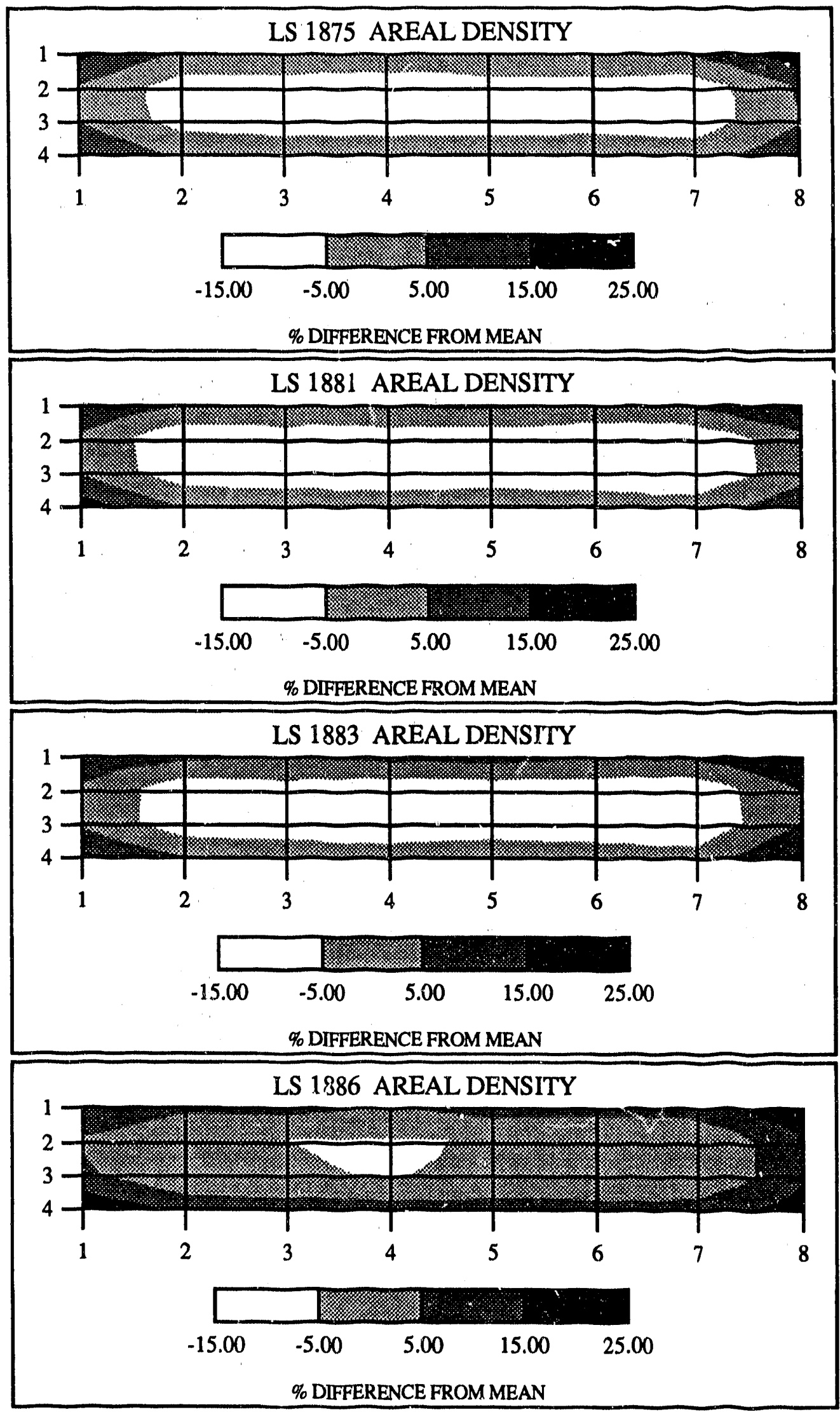

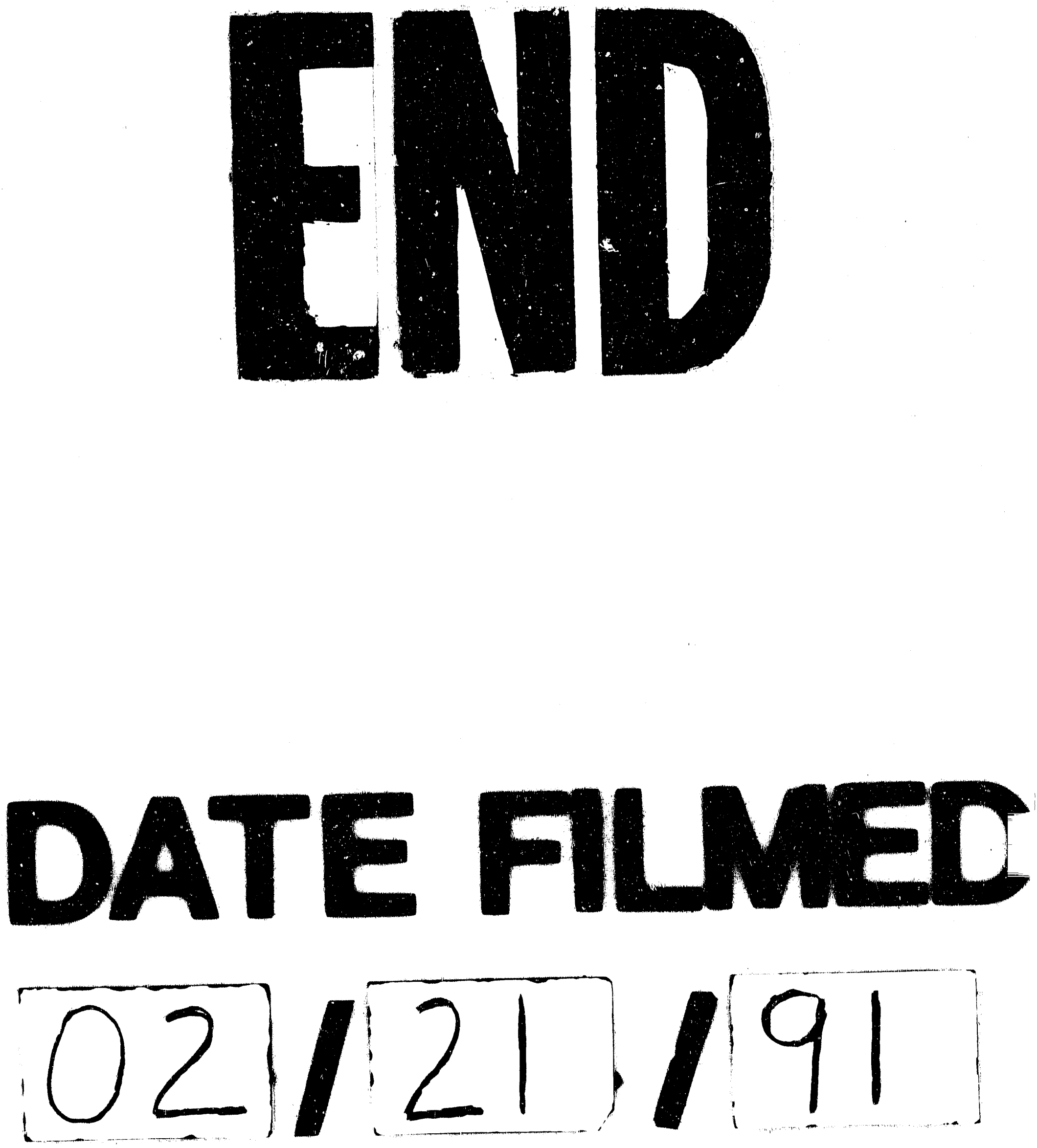
